\title{
Measuring oxygen saturation and pulse rate in dairy cows before and after machine milking using a low-cost pulse oximeter
}

\author{
Aldo Calcante, ${ }^{1}$ Francesco M. Tangorra ${ }^{2}$ \\ ${ }^{1}$ Department of Agricultural and Environmental Sciences; ${ }^{2}$ Department of Veterinary Science for Health, Animal \\ Production and Food Safety, Università degli Studi di Milano, Milano, Italy
}

\begin{abstract}
The present study was aimed at measuring the haemoglobin oxygen saturation and the pulse rate on dairy cow teats before and after milking, using a bespoke low-cost pulse oximeter.

The pulse oximeter was tested in a three-day field test involving 18 Holstein Friesian cows raised in a commercial farm located in Northern Italy.

The results highlighted a significant difference both in haemoglobin oxygen saturation $\left(\mathrm{SpO}_{2}\right)$ and pulse rate before and after milking in the entire sample of animals. By dividing the sample according to the milking time (fast $<8 \mathrm{~min}$ and slow $>8 \mathrm{~min}$ ), a significant difference between fast and slow cows was observed for $\mathrm{SpO}_{2}$, whilst no difference was identified in relation to their lactation stage $[<70$ days in milking (DIM) and 71-140 DIM]. As to the pulse rate, milking time and lactation stage were not significantly different. This confirms that machine milking can create stress to the teat causing tissue circulatory impairment and pulse oximetry could be useful for detecting machine milking-induced alterations of teats.

In the future, the pulse oximeter could be used as part of a milking machine monitoring system in order to change operating parameters to minimize the mechanical stress on the teats.
\end{abstract}

\section{Introduction}

As is well-known, the teat cup is the interface between the milking machine and dairy cow teat. The attempt to emulate with a milking machine the rhythmic process of a calf suckling (a milk-

Correspondence: Aldo Calcante, Department of Agricultural and Environmental Sciences, Università degli Studi di Milano, via Celoria 2, 20133 Milano, Italy.

E-mail: aldo.calcante@unimi.it

Key words: Dairy cows; haemoglobin oxygen saturation; machine milking; pulse oximeter; pulse rate.

Received for publication: 28 January 2021.

Accepted for publication: 6 May 2021.

(C) Copyright: the Author(s), 2021

Licensee PAGEPress, Italy

Journal of Agricultural Engineering 2021; LII:1155

doi:10.4081/jae.2021.1155

This article is distributed under the terms of the Creative Commons Attribution Noncommercial License (by-nc 4.0) which permits any noncommercial use, distribution, and reproduction in any medium, provided the original author(s) and source are credited. ing phase alternated with a massage phase according to the pulsation ratio) has only been partially successful. The teat inside the liner is under continuous vacuum, and the vacuum under the teat is subject to dynamic changes due to its cyclical liner movement managed by the pulsator (Odorcić et al., 2019). As a consequence, mechanical milking can cause circulatory changes (congestion and/or oedema) with accumulation of fluid in the capillaries or in the teat tissue, which causes an increase in teat wall thickness and teat skin temperature (Hamann et al., 1994; Tangorra et al., 2019). Teat problems can be due to various factors, the most important of which are high milking vacuum, unfitting pulsation ratio, and liners conditions (Junga et al., 2016).

Raising the vacuum level from 50 to $70 \mathrm{kPa}$ results in shorter machine-on time, but can also cause an increasing of teat tissue thickness (Hamann and Mein, 1988). In particular, a combination of high vacuum levels and a long liner open phase can potentially increase teat-end congestion (Penry et al., 2017).

An inappropriate pulsation ratio and potential overmilking can worsen circulatory impairment, thus increasing the risk of infections. In particular, an excessive reduction of the d-phase increases teat end congestion, which is an accumulation of fluid in the circulatory pathway, with a reduction in the teat canal cross-section (Upton et al., 2016; Penry et al., 2017). However, if the increase of b-phase duration during the milking phase is matched with an increase of the pulsation rate, teat tissue thickness is decreasing (Hamann and Mein, 1996). Many studies (Hillerton et al., 2000; Ohnstad et al., 2007) have highlighted that wide bore, aged and high tensioned liners as well as large mouthpiece chamber and small lip diameter can be stress factors for the teat.

The most important short-term changes caused by circulatory impairment are discoloured teats, ringing, swelling and opening of the teat canal and, if the problem persists over time, hyperkeratosis (Odorcić et al., 2019). In the long term the incidence of mastitis can potentially increase, with a consequent reduction of milk yield and quality, an increase of costs for veterinary services and medicine and an overall reduction of farm profitability and animal welfare (Tangorra et al., 2019).

In this context, the haemoglobin oxygen saturation could be used as an indicator to assess the milking machine-induced mechanical stress on the teats due to incorrect settings.

In human and veterinary medicine, haemoglobin oxygen saturation is used to estimate the health status and guide therapeutic decisions (Detry et al. 2003). In particular, haemoglobin oxygen saturation measured in healthy cows, expressed as a percentage of $\mathrm{SpO}_{2}$, is higher than $95 \%$ (Detry et al., 2003), whereas lower values indicate health problems and/or physical stress for the animal.

In a study carried out by Detry et al. in 2003, a gas analyser was used to measure haemoglobin oxygen saturation in Belgian White and Blue calves. This method, which was widespread at that time, needs a little arterial blood draw, and the use of a complex and expensive instrumentation. An alternative method that in human medicine has been established for years is the use of the pulse oximeter. This device provides an immediate and non-inva- 
sive measurement of haemoglobin oxygen saturation also in cattle. Coghe et al. (1999) compared the values of arterial oxygen saturation measured through a gas analyser and a pulse oximeter in cattle, and did not observe any statistical difference between the results obtained with the two methods. Uystepruyst et al. (2000) conducted a study to verify and confirm the reliability of the pulse oximeter on a sample of newly-born calves. The haemoglobin oxygen saturation was measured using a pulse oximeter applied to the tail base, and a gas analyser on a little blood draw from the subclavian artery. The results are consistent with those obtained by Coghe et al. in 1999 and the regression between values obtained using the two different devices was highly significant $\left(\mathrm{R}^{2}=0.87\right)$. Grosenbaugh et al. in 2007 compared the haemoglobin absorbance spectra from common domestic species with that of human haemoglobin. This study highlighted that the spectral properties of bovine haemoglobin do not differ significantly from those of human haemoglobin and should not be a limiting factor in the use of a pulse oximeter, based on human algorithms, to animal species.

Bleul and Kahn (2008) found a high correlation ( $\mathrm{r}=0.92)$ between $\mathrm{SpO}_{2}$ values measured using a pulse oximeter and a gas analyser confirming the reliability of the pulse oximeter applied in the zootechnical field in accordance with the conclusions reached by Uystepruyst et al. (2000). In particular, Uysterpruyst et al. (2000) demonstrated the possibility of $\mathrm{SpO}_{2}$ measurement in calves using a pulse oximeter designed for humans. Recently, Kanz et al. (2018) used a pulse oximeter for continuous monitoring of arterial oxygen saturation and pulse in newborn Holstein Friesian calves.

Given the ability and the practicality of haemoglobin oxygen saturation measurement using a pulse oximeter, this approach could be adopted to evaluate the mechanical stress on teats due to the milking operation. In fact, as previously discussed, the stress caused by the milking machine affects the blood flow in teats, with consequent variation in oxygen saturation in tissues.

Maltz et al. (2000) investigated the relationship between blood flow and oxygen concentration of teat-end tissue before and after machine milking using a pulse oximeter, but no significant differences in post versus pre-milking oxygen concentration measures were found.

Recently, Wieland et al. (2020) have studied the changes induced by machine milking in blood circulation in the teats using power Doppler sonography on 109 Holstein dairy cows. The authors observed that blood flow increased after pre-milking udder preparation, but decreased immediately after the unit detachment probably due to the mechanical stress caused by the milking machine on teat-end tissues.

The present study is aimed at measuring haemoglobin oxygen saturation - expressed as a percentage of $\mathrm{SpO}_{2}$ - and the pulse rate on the teat of dairy cows before and after milking, using a bespoke low cost $(<50 €)$ pulse oximeter. In perspective, this device could be used as part of the milking machine monitoring system, with the possibility of adjusting operating parameters in order to minimize the mechanical stress on the teats.

\section{Materials and methods}

The present study was carried out in a commercial farm in Northern Italy with 100 lactating Italian Holstein Friesian cows. At this farm, cows are milked in a double-7 herringbone milking parlour (DeLaval, Tumba, SWE) set with a 60 cycles/min pulsator rate and a $50 \%$ pulsator ratio with a nominal vacuum of $42 \mathrm{kPa}$ kept constant by a variable-speed vacuum pump. For the experimental tests, 18 Italian Holstein Friesian dairy cows (DIM, days in milking, $82 \pm 29 \mathrm{~d}$, ranging from 40 to $136 \mathrm{~d}$; lactation 1-4) were enrolled. All cows were born and bred at the same farm and managed with the same feeding and nutritional scheme.

The sample size was calculated for oxygen saturation considering an average value of $98 \%$ before milking, and a reduction up to $95 \%$ after milking as the threshold of potential stress, according to Detry et al. (2003). The minimum number of cows was calculated based on the following assumptions: power $80 \%$, level of significance $5 \%$, expected mean and standard deviation of the paired differences 3 and 2 respectively (Dhand and Khatkar, 2014). As to the pulse rate, the sample size was calculated considering an average value of 80 before milking and a relative increase of $15 \%$ during milking as the threshold of for potential stress (Royle et al., 1992; Hopster et al., 1998). As with oxygen saturation, the calculation of the minimum number of cows was based on the following assumptions: power $80 \%$, level of significance $5 \%$, expected mean and standard deviation of the paired differences 12 and 7 respectively (Dhand and Khatkar, 2014).

A MAXREFDES117 (Maxim Integrated, San José, CA, USA) sensor was used for the measurement of haemoglobin oxygen saturation and pulse rate, which was inserted in a measuring system designed and developed at the Department of Agricultural and Environmental Sciences of Università degli Studi di Milano.

MAXREFDES117 is a low power, optical pulse oximeter with two integrated LEDs - a red $(660 \mathrm{~nm})$ light emitting diode and an infrared $(880 \mathrm{~nm})$ light emitting diode - to transmit light through the vascular bed to a photodetector. The difference in the intensity of the transmitted light between the red and infrared lights is caused by the difference in the absorption of light by oxygenated (saturated) and deoxygenated (desaturated) haemoglobin (Maltz et al., 2000). This sensor works with both Arduino and others embedded platforms for quick testing, development and system integration. An open-source heart-rate and $\mathrm{SpO}_{2}$ algorithm is included in a free firmware library provided with the sensor to calculate the amount of oxygen saturation and pulse rate. MAXREFDES117 implements the heart-rate/ $\mathrm{SpO}_{2}$ sensor (MAX30102) commonly used for studies about human health (Telfer et al., 2017; Siam et al., 2019), an efficient low-power step-down converter (MAX1921), and an accurate level translator (MAX14595). The sensor typically operates at less than $5.5 \mathrm{~mW}$, when used with its firmware, and its acquisition rate ranges between 25 and 100 samples per second depending on the embedded platform used. A block diagram of the system implemented is shown in Figure 1.

In our study, the Arduino UNO platform was chosen for its reliability and ease of use. The Arduino microprocessor was programmed using the firmware library provided by Maxim Integrated to communicate with the pulse oximeter and show on a digital display the value of haemoglobin oxygen saturation measured in the dairy cows involved in this study (Figure 2 right). The acquisition rate was set at $25 \mathrm{~Hz}$, and haemoglobin oxygen saturation and pulse rate were calculated based on the average of threesecond measurements (i.e. on 75 samples).

The pulse oximeter (Figure 2 left) was fixed at the end of a 50 $\mathrm{cm}$-long flexible metal rod to make easy and safe measurements.

Haemoglobin oxygen saturation and pulse rate were measured using the pulse oximeter in the right-front teats of the cows, before the attachment of the milking cluster and immediately after its automatic removal, during three consecutive morning milking sessions. The measurements were carried out by placing the pulse oximeter at the contact point between the tissue and the head of the liner (Figure 3). Particular attention was paid to fit the device perfectly in contact with the skin to avoid that any light beam, generated by the LEDs, could disperse causing errors in the measurement. This particular position was chosen because this is where the tissue comes in contact with the liner mouthpiece lip, and is there- 


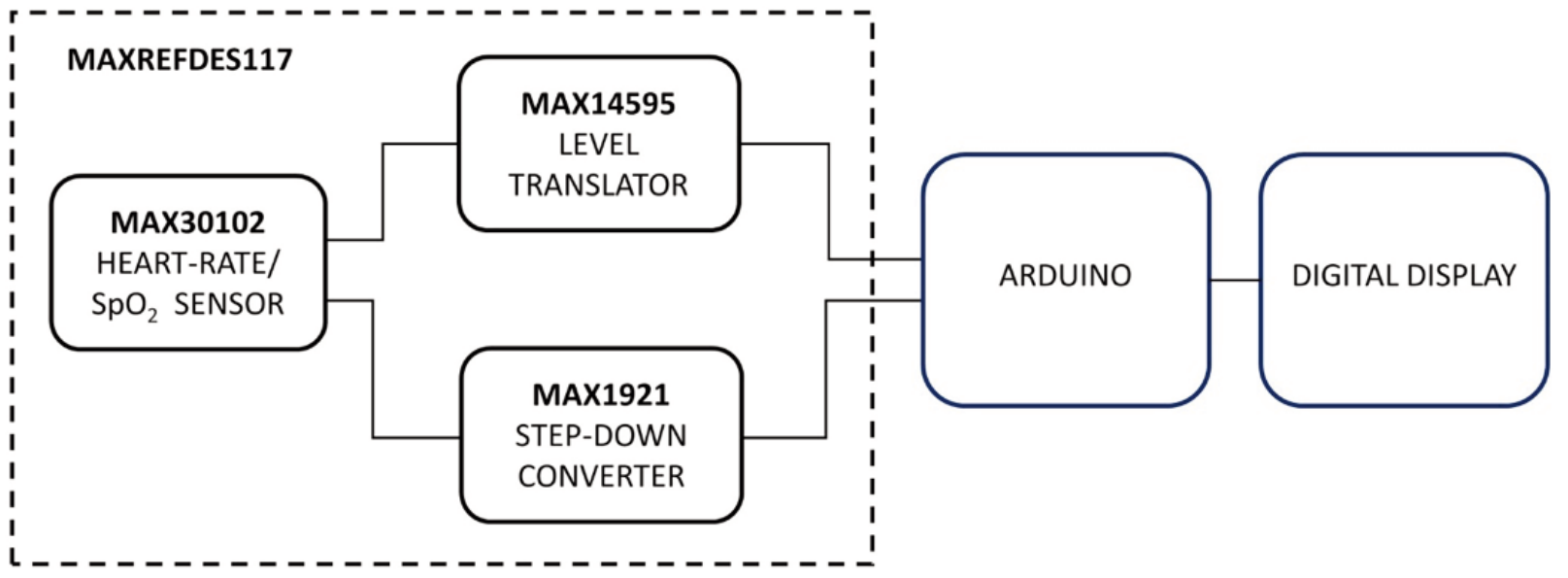

Figure 1. Block diagram of the pulse oximeter sensor and the measuring system used in this study.
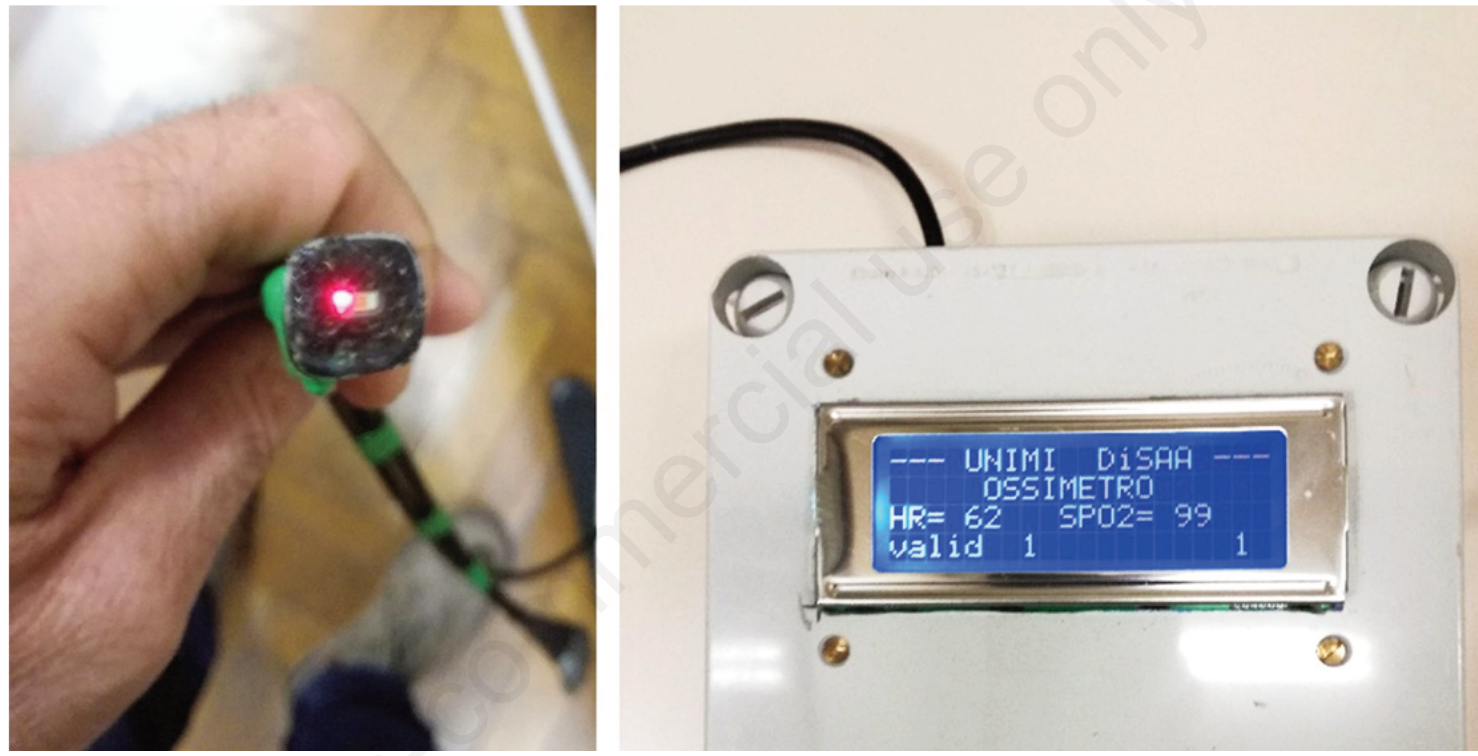

Figure 2. On the left: the pulse oximeter fixed at the top of a $50 \mathrm{~cm}$-long flexible metal rod. On the right: the digital display.

fore subject to high mechanical stress due to the frictional force between the mouthpiece and the teat during the low-flow period toward the end of the milking session. Furthermore, from a practical point of view, since this sensor could be included in a monitoring system of the milking machine, this position (i.e. on the liner mouthpiece) is the best solution to obtain a representative measurement of $\mathrm{SpO}_{2}$ and heart rate, and facilitate the periodic maintenance activities, including cleaning. Finally, the acquisition time needed to obtain a stable reading was about five seconds.

The statistical analysis was carried out using JMP Pro 14 (SAS Institute, Cary, NC, USA). Haemoglobin oxygen saturation and pulse rate data before and after milking were analysed for all teats and separately for teats belonging to cows in early $(<70$ DIM) and mid-lactation (71-140 DIM) and for teats belonging to cows with fast ( $<8 \mathrm{~min})$ and slow ( $>8 \mathrm{~min}$ ) milking times. The Shapiro-Wilk test was used to assess the normality of the measured variables. A paired t-test was used to compare the effects on the teats within the same class; an unpaired t-test was used to compare effects on the teats between classes. Significance was associated with $\mathrm{P}<0.05$.

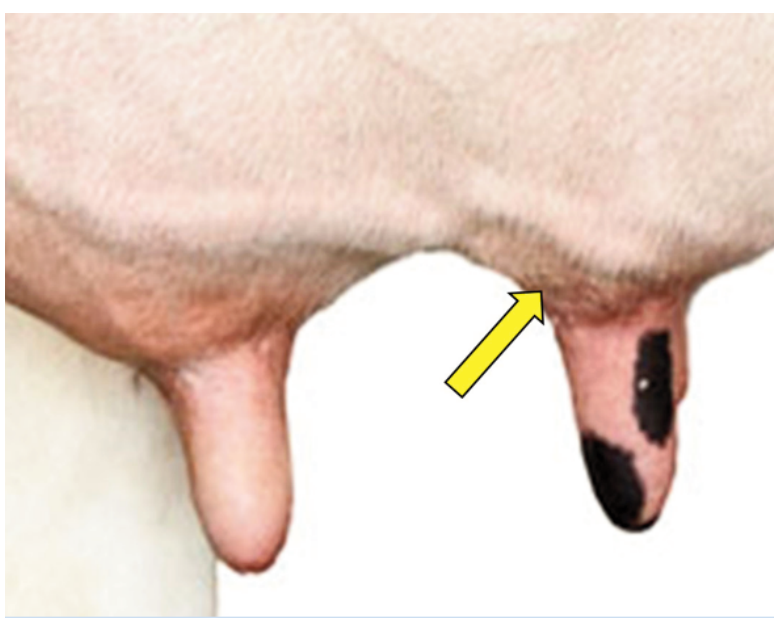

Figure 3. Position (indicated by the arrow) of the measurement point of haemoglobin oxygen saturation and pulse rate. 


\section{Results and discussion}

The average oxygen saturation $\left(\mathrm{SpO}_{2}\right)$ measured on the teat of the dairy cows involved in the field test ranged between 98.4 and $98.9 \%$ before milking and dropped significantly to 93.3 and 93.8\% immediately after the milking cluster detachment (Table 1). These findings differ from those obtained by Maltz et al. (2000), who measured a lower average tissue oxygen concentration at the teat level before milking $(94.6 \pm 1.8 \%)$ and did not find any significant difference with respect to post milking values $(94.9 \pm 1.5 \%)$. This could be due to the different measuring time and site. Maltz et al. (2000) included in the analysis the oxygen concentration data for the first $60 \mathrm{~s}$ after the removal of the milking unit and the measuring site was as close as possible to the teat-end. Our acquisition time corresponded to the time needed to obtain a stable reading (about $5 \mathrm{~s}$ ), while our measurements were taken by placing the pulse oximeter in contact with the tissue close to the insertion point between the udder and the teat. The consistent reduction in $\mathrm{SpO}_{2}$ levels measured in our study after the milking unit removal could be linked to a decrease in teat blood perfusion intensity after machine milking as reported by Kuchler (2011), who attributed this change to the effects of machine milking on the teat tissue and vascularization. Changes of teat skin blood flow dependent on the milking machine settings were reported earlier also by Hamann et al. (1994). More recently, Wieland et al. (2020), in a study aimed to describe machine milking-induced changes in teat blood circulation of dairy cows, found that blood perfusion intensity of teats decreased after machine milking, compared with the value measured after pre-milking udder stimulation. The Authors attributed the circulatory impairment of the teat to vacuum-induced mechanical forces during machine milking. Their hypothesis was corroborated by previous work from their own group (Wieland et al., 2018) and reports from other researchers (Upton et al., 2016; Penry et al., 2017; Odorčić et al., 2019) confirming the idea of a machine milking-induced effect on the circulatory system of the teat. This effect could explain the significant difference we observed in $\mathrm{SpO}_{2}$ measured at the teat level after the milking cluster detachment for cows with fast $(<8 \mathrm{~min})$ and slow $(>8 \mathrm{~min})$ milking times (Table 2). Slow cows showed a higher reduction of $\mathrm{SpO}_{2}$ which ranged between -5.8 and $-6.6 \%$, compared to fast cows that had values between -3.1 and $-3.7 \%$. This confirms that longer milking times can create stress to the teat and cause tissue circulatory impairment. The lactation stage did not affect oxygen saturation. No statistical differences were found in $\mathrm{SpO}_{2}$ after milking for cows in early ( $<70$ DIM) and mid-lactation (71-140 DIM), as summarized in Table 3, suggesting that the oxygen saturation measurement at the teat level is a more suitable parameter for detecting machine milking-induced alterations in the short term

Table 1. T-test of haemoglobin oxygen saturation and pulse rate measured at the teat level before and after milking.

\begin{tabular}{lccccc} 
Variable & Milking & n & $\begin{array}{c}\text { Before millking } \\
\text { Mean } \pm \text { StD }\end{array}$ & $\begin{array}{c}\text { After milking } \\
\text { Mean } \pm \text { StD }\end{array}$ & P-value \\
$\mathrm{SpO}_{2}(\%)$ & 1 & 18 & $98.4 \pm 0.7$ & $93.8 \pm 2.0$ & $<0.0001$ \\
& 2 & & $98.9 \pm 1.0$ & $93.8 \pm 2.1$ & $<0.0001$ \\
& 3 & & $98.6 \pm 1.2$ & $93.3 \pm 2.7$ & $<0.0001$ \\
Pulse rate (bpm) & 1 & 18 & $86.2 \pm 13.6$ & $77.4 \pm 10.9$ & 0.0137 \\
& 2 & & $94.3 \pm 15.3$ & $73.9 \pm 11.7$ & 0.0296 \\
& 3 & & $86.1 \pm 17.1$ & & 0.0132 \\
\hline
\end{tabular}

$\mathrm{StD}$, standard deviation.

Table 2. T-test on the differences of haemoglobin oxygen saturation and pulse rate at the teat level between before and after milking for cows with fast $(<8 \mathrm{~min})$ and slow ( $>8 \mathrm{~min})$ milking times.

\begin{tabular}{|c|c|c|c|c|c|c|}
\hline \multirow[t]{3}{*}{ Variable } & \multirow[t]{3}{*}{ Milking (n) } & \multicolumn{4}{|c|}{ Milking time (min) } & \multirow[t]{3}{*}{ P-value } \\
\hline & & \multicolumn{2}{|c|}{ Fast } & \multicolumn{2}{|c|}{ Slow } & \\
\hline & & n & Mean \pm StD & n & Mean \pm StD & \\
\hline \multirow[t]{3}{*}{$\mathrm{SpO}_{2}(\%)$} & 1 & \multirow[t]{3}{*}{8} & $-3.1 \pm 1.0$ & \multirow[t]{3}{*}{10} & $-5.8 \pm 1.4$ & 0.0002 \\
\hline & 2 & & $-3.2 \pm 1.5$ & & $-6.6 \pm 1.3$ & 0.0001 \\
\hline & 3 & & $-3.7 \pm 1.4$ & & $-6.6 \pm 2.5$ & 0.0070 \\
\hline \multirow[t]{3}{*}{ Pulse rate (bpm) } & 1 & \multirow[t]{3}{*}{8} & $-6.4 \pm 11.2$ & \multirow[t]{3}{*}{10} & $-10.7 \pm 15.5$ & 0.5022 \\
\hline & 2 & & $-6.1 \pm 4.2$ & & $-7.5 \pm 5.0$ & 0.5344 \\
\hline & 3 & & $-6.7 \pm 14.9$ & & $-16.6 \pm 21.0$ & 0.2628 \\
\hline
\end{tabular}

StD, standard deviation.

Table 3. T-test on the differences of haemoglobin oxygen saturation and pulse rate at the teat level between before and after milking for cows in early (<70 days in milking) and mid-lactation (71-140 days in milking).

\begin{tabular}{|c|c|c|c|c|c|c|}
\hline Variable & Milking (n) & $\mathrm{n}$ & $\begin{array}{l}\text { Early lactation } \\
\text { Mean } \pm \text { StD }\end{array}$ & n & $\begin{array}{l}\text { Mid lactation } \\
\text { Mean } \pm \text { StD }\end{array}$ & P-value \\
\hline $\mathrm{SpO}_{2}(\%)$ & $\begin{array}{l}1 \\
2 \\
3\end{array}$ & 9 & $\begin{array}{l}-3.8 \pm 1.5 \\
-4.7 \pm 2.4 \\
-4.3 \pm 1.9\end{array}$ & 9 & $\begin{array}{l}-5.3 \pm 1.9 \\
-5.6 \pm 1.7 \\
-6.2 \pm 2.9\end{array}$ & $\begin{array}{l}0.0939 \\
0.4425 \\
0.1239\end{array}$ \\
\hline Pulse rate (bpm) & $\begin{array}{l}1 \\
2 \\
3\end{array}$ & 9 & $\begin{array}{c}-13.0 \pm 14.5 \\
-6.0 \pm 10.9 \\
-8.0 \pm 17.9\end{array}$ & 9 & $\begin{array}{c}-4.6 \pm 11.9 \\
-7.8 \pm 14.2 \\
-16.5 \pm 19.6\end{array}$ & $\begin{array}{l}0.1954 \\
0.7698 \\
0.3545\end{array}$ \\
\hline
\end{tabular}

StD, standard deviation. 
rather than in medium and long term.

The average pulse rate measured at the teat level before and after milking ranged respectively between 86.1 and $94.3 \mathrm{bpm}$ and between 73.9 and $87.4 \mathrm{bpm}$ (Table 1). These values are consistent with those reported in literature and measured during milking (Hopster et al., 1998) and before and after milking (Maltz et al., 2000) for Holstein Freisian dairy cows. The average pulse after milking was significantly lower than before probably because of the milk let-down response, as reported by Maltz et al. (2000).

Milking time and lactation stage did not influence the pulse rate (Table 3 ). No statistical differences were found in pulse rate after milking for cows with fast $(<8 \mathrm{~min})$ and slow $(>8 \mathrm{~min})$ milking times and for cows in early ( $<70$ DIM) and mid-lactation (71140 DIM), suggesting that other factors can affect the heart rate variability including human-animal interactions, agonistic interactions in the milking parlour holding area and management procedures during milking.

\section{Conclusions}

The aim of this study was to develop a low-cost pulse oximeter and evaluate if the haemoglobin oxygen saturation $\left(\mathrm{SpO}_{2}\right)$ and pulse rate values measured at the teat level before and after milking showed any significant difference.

The results obtained from a field test involving 18 Holstein Friesian cows highlighted that there is a significant difference both in haemoglobin oxygen saturation and in pulse rate before and after milking for the entire sample of animals. By dividing the sample according to the milking time, a significant difference between fast and slow cows was observed for $\mathrm{SpO}_{2}$, whilst no difference was noted considering the lactation stage.

As to the pulse rate, it was only possible to identify a declining trend of the values measured before and after milking, but no significance was demonstrated for milking time and lactation stage.

In conclusion, this study confirms that machine milking can create stress to the teat and cause circulatory impairment in its tissue and that pulse oximetry could be useful for detecting machine milking-induced alterations of the teats. In perspective, the measurement of the haemoglobin oxygen saturation by a pulse oximeter sensor inserted at the top of the liner mouthpiece in close contact with the udder could be used to avoid long-term effects on the teat tissue caused by inadequate milking machine settings (e.g. vacuum level, pulsation ratio), and could provide useful information about the health of the cows. The future steps of this study will consist in the implementation of the pulse oximeter into a commercial liner (on the mouthpiece head, in contact with the tissue of the udder) and in a series of tests to be carried out by varying the operating parameters of the milking machine in order to verify whether it is actually possible to minimize mechanical stress due to the milking.

\section{References}

Bleul U., Kahn W. 2008. Monitoring the bovine fetus during stage II of parturition using pulse oximetry. Theriogenology 69:30211.

Coghe J., Uystepruyst C., Bureau F., Lekeux P. 1999. Non-invasive assessment of arterial haemoglobin oxygen saturation in cattle by pulse oximetry. Vet. Rec. 145:666-9.

Detry B., Cambier C., Frans A., Gustin P., Clerbaux T. 2003. Calculation of bovine haemoglobin oxygen saturation by algorithms integrating age, haemoglobin content, blood $\mathrm{pH}$, partial pressures of oxygen and carbon dioxide in the blood, and temperature. Vet. J. 165:258-65.

Dhand N.K., Khatkar M.S. 2014. Statulator: an online statistical calculator. Available from: http://statulator.com

Grosenbaugh D.A., Alben J.O., Muir W.W. 2007. Absorbance spectra of inter-species hemoglobins in the visible and near infrared regions. J. Vet. Emerg. Crit. Care. 7:36-42.

Hamann J., Burvenich C., Mayntz M., Osteras O., Haider W. 1994. Machine-induced changes in the status of the bovine teat with respect to the new infection risk. Teat Tissue Reactions to Machine Milking and new Infection Risk. Bull. Int. Dairy Feder. 297:13-22.

Hamann J., Mein G.A. 1988. Responses of the bovine teat to machine milking: measurement of changes in thickness of the teat apex. J. Dairy Res. 55:331-8.

Hamann J., Mein G.A. 1996. Teat thickness changes may provide biological test for effective pulsation. J. Dairy Res. 63:179-89.

Hillerton J.E., Ohnstad I., Baines J.R., Leach K.A. 2000. Changes in cow teat tissue created by two types of milking cluster. J. Dairy Res. 67:309-17.

Hopster H., van der Werf J.T.N, Blokhuis J.H. 1998. Side preference of dairy cows in the milking parlour and its effects on behaviour and heart rate during milking. Appl. Anim. Behav. Sci. 55:213-29.

Junga P., Travnicek P., Ruzbarsky J. 2016. Monitoring of the machine milking process with application of infrared thermography. MM Sci. J. 2016:985-9.

Kanz P., Krieger S., Drillich M., Iwersen M. 2018. Technical note: evaluation of a wireless pulse oximeter for measuring arterial oxygen saturation and pulse rate in newborn Holstein Friesian calves. J. Dairy Sci. 101:6437-42.

Kuchler K. 2011. Investigation of the effects of milking on the teat tissue and the teat blood flow using ultrasonographic scanning and color angiography [Der Einfluss des Melkens auf Durchblutung und Morphologie der Rinderzitze untersucht mittels Color Angiographie und B-Mode Sonographie]. In Zentrum für Klinische Tiermedizin der Tierärztlichen Fakultät. Vol. Dr. Vet. Med. Ludwig-Maximilians-Universität München, Munich.

Maltz E., Reinemann D.J., Davis M.A. 2000. Blood flow and oxygen concentration of teat-end tissue before and after machine milking, ASAE annual International Meeting, Milwaukee, WI, USA, Paper No. 003012.

Odorcić M., Rasmussen M.D., Paulrud C.O., Bruckmaier R.M. 2019. Milking machine settings, teat condition and milking efficiency in dairy cows. Animal. 13:94-9.

Ohnstad I., Mein G.A., Baines J.R., Rasmussen M.D., Farnsworth R., Pocknee B.R., Hemling T.C., Hillerton J.E. 2007. Addressing teat condition problems. pp 189-199 in Proc. National Mastitis Council Annual Meeting, San Antonio, TX, USA.

Penry J.F., Upton J., Mein G.A., Rasmussen M.D., Ohnstad I., Thompson P.D., Reinemann D.J. 2017. Estimating teat canal cross-sectional area to determine the effects of teat-end and mouthpiece chamber vacuum on teat congestion. J. Dairy Sci. 100:821-7.

Royle C., Garnsworthy P.C., McArthur A.J., Mepham T.B. 1992. Effects of frequent milking on heart rate and other physio-logical variables in dairy cows. pp 237-243 in Proc. Prospects for Automatic Milking, Wageningen, The Netherlands.

Siam A.I., Elazm A.A., El-Bahnasawy N.A., El Banby G., Abd ElSamie F.E. 2019. Smart health monitoring system based on IoT and cloud computing. pp 37-42 in Proc. 1st International Conference on Electronic Engineering ICEEM2019, Menoufia University, Egypt. 
Tangorra F.M., Redaelli V., Luzi F., Zaninelli M. 2019. The use of infrared thermography for the monitoring of udder teat stress caused by milking machines. Animals. 384:1-13.

Telfer B., Hoyt R., Lacirignola J., Patel T., Siegel A., Swiston A., Singh N., Trebicka R., Weston C., Williamson J. 2017. Wearable oximetry for harsh environments. pp 107-110 in Proc. 2017 IEEE 14th International Conference on Wearable and Implantable Body Sensor Networks (BSN), Eindhoven, The Netherlands.

Upton J., Penry J.F., Rasmussen M.D., Thompson P.D., Reinemann D.J. 2016. Effect of pulsation rest phase duration on teat end congestion. J. Dairy Sci. 99:3958-65.
Uystepruyst C., Coghe J., Bureau F., Lekeux P. 2000. Evaluation of accuracy of pulse oximetry in newborn calves. Vet. J. 159:71-6.

Wieland M., Nydam D.V., Älveby N., Wood P., Virkler P.D. 2018. Short communication: Teat-end shape and udder-level milking characteristics and their associations with machine milking induced changes in teat tissue condition. J. Dairy Sci. 101:11447-54.

Wieland M., Shirky S., Gioia G., Sipka A., Virkler P.D., Nydam D.V., Älveby N., Porter I.R. (2020). Blood perfusion of teat tissue in dairy cows: Changes associated with pre-milking stimulation and machine milking. J. Dairy Sci. 103:1-12. 